\title{
ALTERNATIVE MEASURES OF MACROECONOMIC IMBALANCES IN THE EU - DESIGN AND VERIFICATION
}

\author{
Stanislav Kološta, Pavol Král', Filip Flaška
}

\section{Introduction}

Years 2008 and 2009 were particularly affected by the outbreak of the global economic recession which in addition to economic instability was also affected by political instability. Economies of most countries in the world felt the impact of the financial crisis, not excluding the EU countries. Since the start of the crisis, there has been a substantial reduction in the EU's growth potential. In the EU, this was reflected at the macro-level by $4.74 \%$ GDP reduction in 2009 (Campos-Soria, Inchausti-Sintes \& EugenioMartin, 2014). The high levels of external liabilities and private and public debt in many countries in the EU still constitute substantial vulnerabilities for growth, jobs and financial stability. The development of various indicators at micro and macro levels in times of last crisis in various countries was investigated by several authors (Campos-Soria, Inchausti-Sintes, \& Eugenio-Martin, 2015; Gugler, Weichselbaumer, \& Zulehner, 2015; Zhao, Jiang, \& Li, 2014; Tatulescu \& Patruti, 2014; Mazurek \& Mielcová, 2017; Klepáč \& Hampel, 2018). In recent years, partial examination of indicators of macroeconomic imbalances in the EU or OECD countries has focused, for example, on the (im) balance of the current account balance (Gosse \& Serranita, 2014; Angelini \& Farina, 2012; Zozri, Chudík, \& Dieppe, 2012), employment (Querimi \& Sergi, 2017; Markovitz, Boer, \& Van Dick, 2014), external imbalances (Fogli \& Perri, 2015; Mauro \& Pappada, 2014), labor productivity (Auzina-Emsina, 2014), the trade imbalance (Begler \& Nitsch, 2014), setting-up wages and prices (Angelini, Dieppe, \& Pierluigi, 2015), or the satisfaction of citizens in relation to macroeconomic indicators (Stracca, 2014).

The European Commission monitors the development of indicators of macroeconomic imbalances within the "alert mechanism report" (AMR) in which indicators of macro-economic imbalances (MI) are assessed across EU Member States (i.e. "Macroeconomic Imbalance Procedure" MIP). MIP was established in December 2011 and implemented for the first time in 2012 as a consequence of economic and financial crisis. Its aim is detection, prevention and correction of macroeconomic imbalances including financial stability of EU countries. It is based on two regulations No. 1176/2011 and No. 1174/2011 within the so-called "Six-pack" aimed at improving the economic governance of the EU. MIP should identify macroeconomic trends which should be instrumental in taking appropriate policy responses to mitigate and manage macroeconomic imbalances (AMR, 2014). European Union economic policy frameworks rely more than ever on timely and high quality socio-economic and financial statistics in member states however its quality varies. Macroeconomic imbalances are thus reflected at national level in various forms and affect mainly the capacity of each economy to generate strong and sustainable growth and create jobs.

MIP could be considered for alert mechanism based on the evolution trends of monitored headline and auxiliary indicators. Based on the development of indicators monitored in the MIP the AMR gives the European Commission recommendations to Member States for the adoption of effective solutions which should be accompanied by a comprehensive and coordinated policy procedures and decisions (AMR, 2015, p. 2). The lack of timely and decisive macroeconomic policy action - to correct domestic and external imbalances - could led to the financial crisis and the Great Recession (Catte, Cova, Pagano, \& Visco, 2011) so they are very likely to have farreaching consequences on economic and social life. Selection of indicators and their monitoring, evaluation and feedback are important for 
the economic, financial and social stability of the EU and individual EU member states (see for example studies of Babecký et al. (2012), Csortos and Szalaj (2014), Domonkos et al. (2017) and Li (2018)). These indicators of macroeconomic imbalances are also subject of criticism (Coolington, 2012; 2013); on the other hand in the EU there exists political consensus for its evaluation and practical evidence. Therefore, it is meaningful to make contribution within $\mathrm{Ml}$ assessment.

The evaluation of indicators of the macroeconomic imbalances should give an overall picture about development of at least headline macroeconomic indicators as well as about the development of individual indicators. Each indicator in AMR reports is reported separately for each EU country and vice versa. From AMR data, we can get picture about the evolution of different MI indicators in the EU, but complete picture about the overall situation of individual countries in the field of macroeconomic imbalances is missing. Therefore, we focused on design and verification of suitable alternative evaluation tool which AMR lacks, and which could be usable for decision making processes within European Commission. Therefore we decided to build on the Knedlik and Schwainitz (2011) who proposed to combine as many meaningful single indicators as possible in one composite indicator as a tool of monitoring of economic and financial stability.

The main aim of this article is to propose aggregated and partial indices of macroeconomic imbalances (MI) and to provide an alternative complex evaluation tool of each EU country on its global position in at least the headline or scoreboard indicators. From the proposed indices we expect fast and simple look on evolution of $\mathrm{Ml}$ in EU countries, to make them more comprehensible for wider use, and to propose simple feedback tool measuring progress of EU member states towards improving the macroeconomic balance including stability in financial sectors. Such comprehensive evaluation and monitoring can be helpful in evaluating the efficiency and effectiveness of the measures taken to eliminate the negative developments in macroeconomic balance that jeopardize the proper functioning of economic and monetary union, as stated in $\operatorname{AMR}(2015$, p. 2).

The rest of the paper is arranged as follows. In section two, we describe data used to derive macroeconomic imbalance indices. In section three, we present methodology we used to develop derive the indices. In section four, we discuss the results. Finally, section five draws some conclusions.

\section{Data Description}

The AMR uses a scoreboard of fourteen headline indicators including new employment indicators plus a wider set of auxiliary indicators (review of all indicators contains statistical annexes of AMR). New employment indicators were not included in our research due to our focus on general external and internal imbalance. These new indicators were previously auxiliary and have been added in 2016 to the headline MIP scoreboard to complement the information provided by the unemployment indicator already included within internal imbalance headline indicators (AMR, 2016). Indicator of internal imbalance "\% change in deflated house prices" was excluded due to data incompleteness in many countries. In our case, indicators 1-5 represent external imbalances (In1-5) while indicators 6-10 represent internal imbalances (In6-10). These indicators focus on the most relevant dimensions of macroeconomic imbalances and competitiveness losses. With reference to AMR we logically assume the desirable direction of chosen headline indicators as presented in Tab. 1 (+/- means that growing/decreasing values of indicator have positive impact on aggregated $\mathrm{Ml}$ index, i.e. values of aggregated $\mathrm{Ml}$ index increases).

For design and verification of proposed methodology an annual data for variables were used from Chapter 3 of the statistical annex of AMR 2015 (we use one year data which were not averaged). We worked with official data from Eurostat and for design and verification of our indices 2004-2013 time periods were used. Indices were computed from values of headline MI indicators of years 2004-2012; year 2008 means cut point of pre-crisis and crisis period; values of $\mathrm{Ml}$ indicators from 2013 were used for verification of proposed mean MI indices from its interpretative capability point of view. We count all estimated values for real data. Malta and Poland were eliminated from our analysis for the year 2004 and Luxembourg for the period 2004-2007 due to lack of data in various headline indicators. The interconnections among EU economies lead us to conservative interpretations of our results. 


\section{Tab. 1: Overview of used headline MI indicators in EU}

\begin{tabular}{c|l|l|l} 
Premise & \multicolumn{1}{|c|}{ Headline indicator } & $\begin{array}{c}\text { Unit } \\
\text { of measure }\end{array}$ & \multicolumn{1}{|c}{ Threshold } \\
\hline+ & Current account balance $-\ln 1$ & $\%$ of GDP & $-4 \% /+6 \%$ of GDP (euro/non-euro area) \\
\hline+ & Net international investments $-\ln 2$ & $\%$ of GDP & $-35 \%$ of GDP \\
\hline- & Real effective exchange rate $-\ln 3$ & $\%$ change & $+-5 \% /+-11 \%$ (euro/non-euro area) \\
\hline+ & Export market shares $-\ln 4$ & $\%$ change & $-6 \%$ \\
\hline- & Nominal unit labor costs $-\ln 5$ & $\%$ change & $+9 \% /+12 \%$ (euro/non-euro area) \\
\hline- & Private credit sector flow $-\ln 6$ & $\%$ of GDP & $14 \%$ of GDP \\
\hline- & Private sector debt $-\ln 7$ & $\%$ of GDP & $133 \%$ of GDP \\
\hline- & General governance sector debt $-\ln 8$ & $\%$ of GDP & $60 \%$ GDP \\
\hline- & Unemployment rate $-\ln 9$ & $\%$ & $10 \%$ \\
\hline- & Total financial sector liabilities $-\ln 10$ & $\%$ change & $+16.5 \%$ \\
\hline
\end{tabular}

Source: own, using AMR

After outbreak of global crisis indicators Private sector debt, General governance sector debt, Unemployment, Net international investments in average exceeded its thresholds and these indicators can be also included into group of indicators with the highest influence on aggregated Ml index after 2008 (Appendix - Tab. 11). In years 2004-2012 Real effective exchange rate, Nominal unit labor costs and Export market shares (with the exception in 2010) were within thresholds. After 2008 arouse discrepancies among EU countries in indicators of Real effective exchange rate, Export market share, Private credit flows and Total financial sector liabilities. Western EU countries did not show sharp fluctuation of above mentioned indicators directly in 2008 but with 2 year time-lag. If we compare crisis year 2012 with pre-crisis year 2004 we can see deterioration in more than $50 \%$ of EU countries in headline indicators like Unemployment (20\% increase), Private sector debt $(26.75 \%$ increase), General governance sector debt (40\% increase). Global crisis affected the most Export market share (decrease from $-0.1 \%$ to $-4.9 \%$ ) and Net international investments (in more than $50 \%$ of EU countries this indicator was worsen at 200\%). After 2008 more than half of EU countries exceeded thresholds in Net international investments, Private sector debt and General governance sector debt.

\section{Methodology}

The principal component analysis (PCA) can be seen in some sense as a standard method for computing of aggregated indices as it was used for creating many indices of different purpose (e.g. Bolcárová and Kološta (2015) aggregated SD index in EU; Dreher et al. (2006) KOF index of globalization; Florida et al. (2011) global creativity index; Sasaina and Satelli (2012) CPI of Transparency International; Kološta, Sabelová and Král' (2018) aggregated and partial LR indices, ect.). This method enables to reduce the dimensionality of a data set which includes a large number of inter-related variables while retaining as much as possible the variation present in the data set (Jolliffe, 2002, p. 10).

In order to overcome deficiencies within computation and interpretation of indices we decided to use a constrained PCA implemented in the R package nsprcomp (Sigg \& Buhmann, 2008). According Sigg and Buhmann (2008), in the case of constrained PCA we start with the standard problem to get the first principal component, i.e.

$$
\arg \max _{\mathbf{w}} \mathbf{w}^{T} \mathbf{C w} \text {, subject to }\|\mathbf{w}\|_{2}=1
$$

where $C \in R^{D \times D}$ is the positive semi-definite covariance matrix of the data, but we assume two additional constraints imposed on $w$, namely sparsity $\|\mathbf{w}\|_{0} \leq \mathrm{K}^{1}$ and non-negativity $\boldsymbol{w} \geq \mathbf{0}$. 


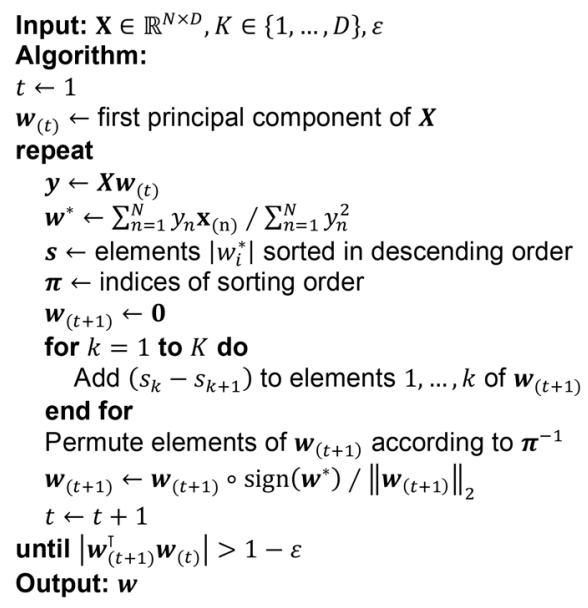

Sigg and Buhmann (2008) proposed the expectation-maximization algorithm (Tab. 2) to find a solution of the above-mentioned problem.

In the original PCA, the first principal component maximizes variance of the projected data, the second principal component maximizes variance of the projected data too but under the constraint that it is orthogonal to the first component, analogously the third principal component maximizes variance and it is orthogonal to the first two components etc. In the case of constrained PCA, the additional constraints allow us to reduce significantly the number of components, and hence to simplify interpretation, trading it for a small loss in explained variance.

We assume that the resulting index should be a linear combination of the original indicators

$$
I=c_{1} \operatorname{In} 1+c_{2} \operatorname{In} 2+\cdots+c_{10} \operatorname{In} 10
$$

preserving as much variability of original data as possible and with coefficients $c_{1}, c_{2}, \ldots, c_{10}$ following premises according to signs listed in Tab. 1. In other words, we are looking for the first principal component with loadings of indicators satisfying some constraints imposed by their expected influence on the index. In order to get $c_{1}, c_{2}, \ldots, c_{10}$, data were standardized, i.e. a correlation matrix was used, because variances of the selected indicators vary in orders of magnitude (Appendix - Tab. 9). Then constraints were enforced on loadings of the original indicators and the first principal component, i.e. index of macroeconomic imbalance (aggregated or overall $\mathrm{MI}$ index) was extracted, separately for each year. The fact, that the proposed MI index possesses properties we require from a good MI measure, can be verified in two ways. First, by its qualitative analysis where we thoroughly interpret the values of the index to see how close these interpretations are to those we can get from individual headline indicators. Second, we can use a multiple time series model to see whether forecasting ability of the index corresponds to our expectation for pre-crisis, crisis and post-crisis periods.

In the paper, for simplicity, we utilize a simple random forest multiple regression model (Breiman, 2001) to create a one-stepahead predictions where a value of the index for a country at time is predicted using values of the index for a country at times $t-1, t-2$ and $t-3$. We also use a country group variable (1 - EU 15, 2 - V4 countries, 3 - other EU countries) as a predictor. Our assumption is that the prediction ability of older values of the index is quite good in pre-crisis period, it deteriorates during a crisis and then it improves once the crisis is retreating.

The basic building block of random regression forests is a regression tree. In the 
paper, we were working with random forest regression where individual regression trees are constructed via CART algorithm, i.e., we assume binary trees where each parent node is split into exactly two child nodes using residual sum of squares (RSS) as a splitting criterion. RSS is defined as follows (Breiman, 2001):

$$
\mathrm{RSS}=\sum_{\mathrm{left}}\left(y_{i}-\bar{y}_{l}\right)^{2}+\sum_{\mathrm{right}}\left(y_{i}-\bar{y}_{r}\right)^{2}
$$

where $\bar{y}_{l}\left(\bar{y}_{v}\right)$ is the mean value of a response variable Y in the left (right) child node, respectively. If we assume that a tree is constructed vertically from top to bottom, the nodes at the bottom are called terminal nodes. The predicted value for each terminal node is then the average value of a response variable for all observations in the node. When constructing a random forest, we fit multiple regression trees to bootstrap samples of the original data sample using the following algorithm in Tab. 3 (Breiman, 2001).

\section{Tab. 3: Algorithm: Random forest regression}

Create $N$ bootstrap samples from the data by selecting $n$ cases at random with replacement.

At each of the bootstrap samples fit a regression tree as follows:

At each node select $\mathrm{m}$ variables at random out of all $M$ possible variables (independently for each node).

Find the best split on the selected $m$ variables.

Average fitted trees to get predictions.

Analogously, indices describing external and internal imbalances were derived using indicators $\ln 1-\ln 5$ (external $\mathrm{MI}$ index) and In6-In10 (internal MI index), respectively. We applied the obtained MI indices for ranking the EU countries. Unfortunately, computation of proposed $\mathrm{Ml}$ indices is quite impractical as for each year we have to run constrained PCA which strongly depends on availability and quality of data. We can eliminate this problem if we replace indices based on coefficients extracted yearly by indices based on average coefficients in a chosen period. We decided to average coefficients from the period 2004-2012 consisting from both pre-crisis and crisis years. Finally, we compared properties of these so called mean based $\mathrm{Ml}$ indices to those based on yearly computed MI indices. All computations were done in statistical software $R$ ( $R$ Core Team, 2016). The data and corresponding $R$ code can be requested from authors.

Weights of headline indicators enable us to monitor changes of its significance impact on aggregated $\mathrm{Ml}$ index over time. Weights of indices have evolved in dependence on intensity of its year to year changes (higher intensity of changes means higher weight and vice versa). Indicators can be divided according to its significance (Tab. 4) into four groups:

1. Stable - Current account balance, Net international investments;

2. Growing influence in crisis - General governance sector debt, Unemployment;

3. Decreasing influence in crisis - Real effective exchange rate, partially also Nominal unit labor costs, Private credit sector flow, Total financial sector liabilities;

4. Negligible impact - Export market shares, Private sector debt.

After outbreak of global crisis, indicators Unemployment and General governance sector debt had the highest weights among internal imbalance indicators, i.e. till 2008 the EU countries avoided major fluctuations of these indicators (Tab. 4).

Each year aggregated $\mathrm{Ml}$ index consists of various composition of components (especially after 2008), which had different yearly based weights. Therefore, we created an index composed of the average weights of each indicator which catch both periods of expansion as well as economic recession. In this way we 
Tab. 4: Weights of individual indicators in the MI index

\begin{tabular}{l|l|l|l|l|l|l|l|l|l|l|l} 
& $\mathbf{2 0 0 4}$ & $\mathbf{2 0 0 5}$ & $\mathbf{2 0 0 6}$ & $\mathbf{2 0 0 7}$ & $\mathbf{2 0 0 8}$ & $\mathbf{2 0 0 9}$ & $\mathbf{2 0 1 0}$ & $\mathbf{2 0 1 1}$ & $\mathbf{2 0 1 2}$ & AVG & STDEV \\
\hline $\ln 1$ & 0.522 & 0.500 & 0.517 & 0.493 & 0.562 & 0.572 & 0.432 & 0.552 & 0.442 & 0.508 & 0.049 \\
\hline $\ln 2$ & 0.443 & 0.340 & 0.352 & 0.385 & 0.562 & 0.203 & 0.052 & 0.552 & 0.573 & 0.381 & 0.175 \\
\hline $\ln 3$ & -0.258 & -0.336 & -0.272 & -0.338 & -0.282 & 0 & 0 & 0 & 0 & -0.164 & 0.159 \\
\hline $\ln 4$ & 0 & 0 & 0 & 0 & 0 & 0 & 0.517 & 0 & 0.162 & 0.075 & 0.174 \\
\hline $\ln 5$ & -0.491 & -0.500 & -0.449 & -0.422 & -0.259 & -0.225 & -0.329 & 0 & 0 & -0.297 & 0.194 \\
\hline $\ln 6$ & -0.256 & -0.196 & -0.392 & -0.360 & -0.377 & -0.548 & -0.374 & 0 & 0 & -0.278 & 0.185 \\
\hline $\ln 7$ & 0 & 0 & 0 & 0 & 0 & 0 & -0.180 & 0 & 0 & -0.021 & 0.060 \\
\hline $\ln 8$ & 0 & 0 & 0 & 0 & 0 & -0.295 & -0.465 & -0.323 & -0.387 & -0.168 & 0.199 \\
\hline $\ln 9$ & -0.240 & -0.098 & -0.016 & -0.024 & -0.281 & 0 & 0 & -0.535 & -0.548 & -0.189 & 0.223 \\
\hline $\ln 10$ & -0.318 & -0.472 & -0.423 & -0.432 & 0 & -0.441 & -0.218 & 0 & 0 & -0.259 & 0.207 \\
\hline
\end{tabular}

Source: own

obtained an aggregated mean $\mathrm{Ml}$ index with weights of all represented headline indicators that can easily calculate the value of the overall MI index substituting values for each country. Indicators that have a high weight in the yearly based aggregated $\mathrm{Ml}$ index remained strong after averaging, and opposite applied for indicators that have little or no weight.

Correlations among aggregated $\mathrm{Ml}$ index constructed on an annual basis (Method 1) with a mean $\mathrm{Ml}$ index using the average weights (Method 2) are in the Tab. 5. We found very strong direct correlation between the aggregated $\mathrm{Ml}$ indices and external $\mathrm{MI}$ indices (constructed using both methods) for all EU countries and however in crisis period correlations reduced (more visible in non-EU countries) it still remained very strong. We deduce that in economically stable period both versions of construction of the Ml index can

\section{Tab. 5: Correlation between MI indices and mean based MI indices}

\begin{tabular}{l|l|l|l|l|l|l|l|l|l}
\multicolumn{1}{c|}{ EU } & $\mathbf{2 0 0 4}$ & $\mathbf{2 0 0 5}$ & $\mathbf{2 0 0 6}$ & $\mathbf{2 0 0 7}$ & $\mathbf{2 0 0 8}$ & $\mathbf{2 0 0 9}$ & $\mathbf{2 0 1 0}$ & $\mathbf{2 0 1 1}$ & $\mathbf{2 0 1 2}$ \\
\hline $\ln 1-\ln 10$ & 0.982 & 0.934 & 0.962 & 0.976 & 0.939 & 0.947 & 0.697 & 0.681 & 0.549 \\
\hline $\ln 1-\ln 5$ & 0.989 & 0.992 & 0.990 & 0.989 & 0.989 & 0.918 & 0.986 & 0.888 & 0.787 \\
\hline $\operatorname{In} 6-\ln 10$ & 0.646 & 0.691 & 0.332 & 0.526 & 0.737 & 0.643 & 0.727 & 0.494 & 0.542 \\
\hline
\end{tabular}

EU 15

\begin{tabular}{l|l|l|l|l|l|l|l|l|l}
\hline $\operatorname{In} 1-\operatorname{In} 10$ & 0.960 & 0.947 & 0.943 & 0.912 & 0.871 & 0.964 & 0.857 & 0.854 & 0.704 \\
\hline $\ln 1-\operatorname{In} 5$ & 0.982 & 0.996 & 0.989 & 0.982 & 0.982 & 0.957 & 1.000 & 0.936 & 0.857 \\
\hline $\operatorname{In} 6-\operatorname{In} 10$ & 0.635 & 0.881 & 0.938 & 0.899 & 0.804 & 0.611 & 0.768 & 0.646 & 0.254 \\
\hline
\end{tabular}

non EU 15

\begin{tabular}{l|l|l|l|l|l|l|l|l|l}
\hline $\operatorname{In} 1-\ln 10$ & 0.964 & 0.918 & 0.962 & 0.967 & 0.846 & 0.890 & 0.835 & 0.456 & 0.412 \\
\hline $\ln 1-\operatorname{In} 5$ & 0.993 & 0.967 & 0.989 & 0.989 & 0.978 & 0.758 & 0.967 & 0.495 & 0.703 \\
\hline $\operatorname{In} 6-\ln 10$ & 0.720 & 0.225 & -0.148 & 0.357 & 0.698 & 0.659 & 0.681 & 0.555 & 0.835 \\
\hline
\end{tabular}


Tab. 6: Weights of individual indicators in the external MI index (In1-5)

\begin{tabular}{c|c|c|c|c|c|c|c|c|c|c|c} 
& $\mathbf{2 0 0 4}$ & $\mathbf{2 0 0 5}$ & $\mathbf{2 0 0 6}$ & $\mathbf{2 0 0 7}$ & $\mathbf{2 0 0 8}$ & $\mathbf{2 0 0 9}$ & $\mathbf{2 0 1 0}$ & $\mathbf{2 0 1 1}$ & $\mathbf{2 0 1 2}$ & AVG & STDEV \\
\hline $\operatorname{In} 1$ & 0.608 & 0.578 & 0.629 & 0.547 & 0.606 & 0.717 & 0.717 & 0.709 & 0.672 & 0.642 & 0.064 \\
\hline $\ln 2$ & 0.512 & 0.487 & 0.477 & 0.500 & 0.569 & 0.697 & 0.581 & 0.706 & 0.690 & 0.580 & 0.095 \\
\hline $\ln 3$ & -0.282 & -0.394 & -0.356 & -0.459 & -0.376 & 0.000 & -0.216 & 0.000 & 0.000 & -0.231 & 0.186 \\
\hline $\ln 4$ & 0.000 & 0.000 & 0.000 & 0.000 & 0.000 & 0.000 & 0.227 & 0.000 & 0.269 & 0.055 & 0.110 \\
\hline $\ln 5$ & -0.538 & -0.523 & -0.500 & -0.491 & -0.410 & 0.000 & -0.224 & 0.000 & 0.000 & -0.298 & 0.242 \\
\hline
\end{tabular}

Source: own

be used; at the time of economic recession for more appropriate alternative computation of aggregated and external $\mathrm{Ml}$ indices we consider first method. Lower and fluctuating values of correlation coefficients were between Internal $\mathrm{MI}$ indices; in this partial index we expect to take for more convenient first method considering the volatility of the balance of components weights. These methodological findings are important for our further investigations.

The average aggregated $\mathrm{Ml}$ index may be used for estimated assessment of MI by substitution of estimated or expected data using average weights. Another possibility how to predict evolution of Ml could by calculation of weights from estimated data using our methodology and, on that basis, determine the prognosis of development of MI in EU countries.

The same methodology was chosen for the construction of partial indices of external and internal MI. This allowed us to investigate not only overall MI among EU countries but also external $\mathrm{Ml}$ and internal Ml. The weights of components of external MI index (Tab. 6) developed in very identical way like weights of aggregated MI index; Current account balance and Net international investments were the most stable again and these indicators have a strong impact on external $\mathrm{Ml}$ index. After outbreak of economic and financial crisis the rest of indicators of external $\mathrm{Ml}$ reduced its impact on external $\mathrm{Ml}$ index with the exception of Export market share.

Differences were between weights of indicators of aggregated MI index and weights of indicators of internal MI index (Tab. 7) - after outbreak of crisis the highest differences were in indicators of Unemployment, Total financial sector liabilities (in both weights increased) and General governance sector debt (weight decreased); none of the internal MI indicators was steadily evolving. Those factors had an impact on the overall development of the aggregated $\mathrm{MI}$ index in individual EU countries as well as on partial $\mathrm{MI}$ indices constructed by both methods.

\section{Results and Discussion}

We start our presentation of results by comparison of the one-head prediction ability of the index based on random forest regression models with our assumption stated in the

Tab. 7: Weights of individual indicators in the internal MI index (In6-10)

\begin{tabular}{l|c|c|c|c|c|c|c|c|c|c|c} 
& $\mathbf{2 0 0 4}$ & $\mathbf{2 0 0 5}$ & $\mathbf{2 0 0 6}$ & $\mathbf{2 0 0 7}$ & $\mathbf{2 0 0 8}$ & $\mathbf{2 0 0 9}$ & $\mathbf{2 0 1 0}$ & $\mathbf{2 0 1 1}$ & $\mathbf{2 0 1 2}$ & $\boldsymbol{A V G}$ & STDEV \\
\hline $\ln 6$ & 0.000 & 0.710 & 0.727 & 0.742 & 0.000 & 0.000 & 0.000 & 0.724 & 0.000 & 0.323 & 0.383 \\
\hline $\ln 7$ & 0.718 & 0.704 & 0.190 & 0.424 & 0.672 & 0.000 & 0.000 & 0.689 & 0.076 & 0.386 & 0.320 \\
\hline $\ln 8$ & 0.000 & 0.000 & -0.659 & -0.520 & -0.079 & -0.305 & -0.407 & 0.000 & 0.000 & -0.219 & 0.259 \\
\hline $\ln 9$ & 0.000 & 0.000 & 0.000 & 0.000 & 0.000 & 0.647 & 0.614 & 0.000 & 0.718 & 0.220 & 0.331 \\
\hline $\ln 10$ & -0.696 & 0.000 & 0.000 & 0.000 & -0.736 & -0.699 & -0.676 & 0.000 & -0.691 & -0.389 & 0.369 \\
\hline
\end{tabular}




\section{Tab. 8: Random forest regression models}

\begin{tabular}{c|c|c|c} 
& Predicted value & Predictors & Variance explained \\
\hline Model 1 & y2007 & y2004, y2005, y2006, group & $88 \%$ \\
\hline Model 2 & y2008 & y2005, y2006, y2007, group & $77 \%$ \\
\hline Model 3 & y2009 & y2006, y2007, y2008, group & NA \\
\hline Model 4 & y2010 & y2007, y2008, y2009, group & $56 \%$ \\
\hline Model 5 & y2011 & y2008, y2009, y2010, group & $52 \%$ \\
\hline Model 6 & y2012 & y2009, y2010 y2011, group & $64 \%$ \\
\hline
\end{tabular}

Source: own

methodology part of the paper. We constructed six random forest models (Tab. 8).

Based on Tab. 8 we can conclude that prediction ability of our index is coherent with our assumption, i.e. it is satisfactory before the crisis, then deteriorates a then slowly recovers after the peak of the crisis.

In the pre-crisis period, most EU countries have positive values of aggregated $\mathrm{MI}$ index calculated by both methods and both indices reacted to the crisis by reducing of values for all countries (Fig. 1). This also applied to partial index of the external MI. Non-EU15 countries have experienced a radical reduction of the values immediately after the outbreak of the crisis, while the EU-15 with one year lapse.

In the aftermath of the first effects of the crisis more than $50 \%$ non-EU countries had higher values of aggregated $\mathrm{Ml}$ index than $75 \%$ of the EU15 countries. In 2011 and 2012 we can see a more balanced value of aggregated MI index, particularly mean based, but up to that time, most EU countries have not reached the pre-crisis levels. In the pre-crisis period were the lowest values of aggregated $\mathrm{Ml}$ indices in Latvia, Estonia, Bulgaria, Romania; after 2008 had the lowest values Portugal, Greece, Spain, Cyprus; the countries with the highest values during all investigated period of time were Denmark, Luxembourg, Netherland, Sweden and Germany. Paradoxically, the best values of the partial internal MI index were in countries with low levels of overall and external MI indices excluding Portugal and Cyprus where values fluctuated. After the outbreak of the crisis, the greater decline was in all indices in non-EU15 countries which responded to the crisis more sensitive and signalized similar trend in EU15 countries where the same scenario took place with one year lag.
Tab. 9 provides colored classification of countries according to reached values of index with comparison of indices constructed by the first and the second method.

If we compare countries like Belgium, Denmark, Netherland, Luxembourg, Austria, Germany, Sweden, Finland and Malta to countries such as Cyprus, Greece, Spain, Portugal, and after 2008 also Italy we will find that the first group of countries shows high values of the aggregated $\mathrm{MI}$ index in comparison to the other group. Also a characteristic feature of the first group of countries is improvement in values of aggregated $\mathrm{Ml}$ index after the first impact of the crisis in 2011 and 2012 - it seems that in these countries were applied measures which properly solved issues of crisis in concrete socio-economic environments, internal structure of markets and position of these countries at global scale can be considered for more stable in comparison with second group of countries mostly from south of the EU. French and Italy had high $\mathrm{Ml}$ index values in the precrisis period but after crisis both countries were not able to reach pre-crises level. Baltic States and Visegrad group showed in general mostly negative aggregated $\mathrm{Ml}$ index values and its development varied - strong weight of longterm deep negative Net international investment position and Current account balance could be one of the factors which keep low or negative values of $\mathrm{Ml}$ indices from long term perspective. UK has reached in 2011-2012 similar values like Baltic and Visegrad countries, while during crisis strong weight of changes in Real effective exchange rate could positively impacts on overall values of both MI indices. Year 2008 showed the onset of the crisis and worsening of $\mathrm{MI}$ index in all EU countries except Netherland, Estonia and UK which on the contrary better 

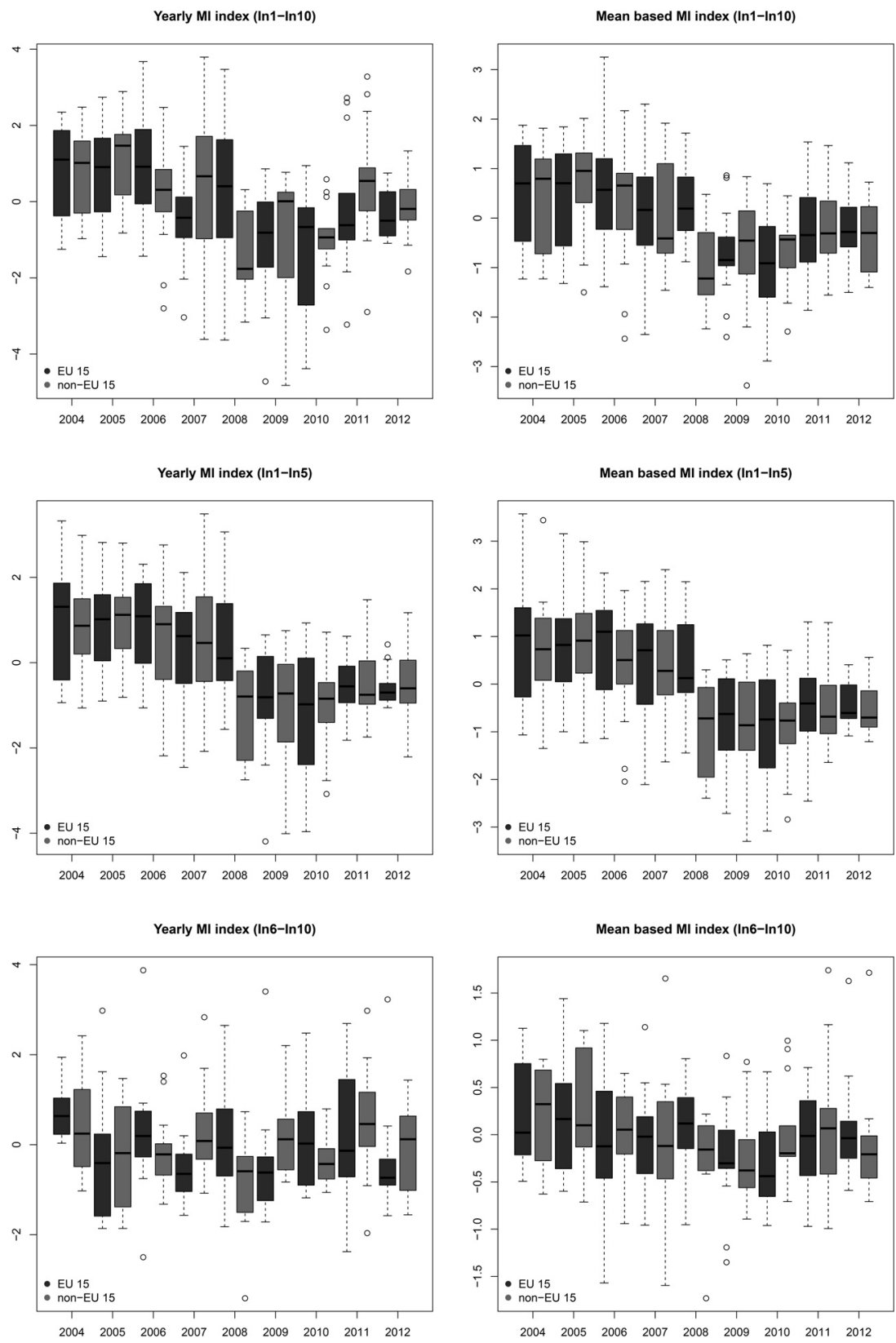


\begin{tabular}{lrrrrrrrrr}
\hline & $\mathbf{2 0 0 4}$ & $\mathbf{2 0 0 5}$ & $\mathbf{2 0 0 6}$ & $\mathbf{2 0 0 7}$ & $\mathbf{2 0 0 8}$ & $\mathbf{2 0 0 9}$ & $\mathbf{2 0 1 0}$ & $\mathbf{2 0 1 1}$ & $\mathbf{2 0 1 2}$ \\
\hline AT & 1.81 & 1.23 & 1.46 & 1.86 & 1.86 & 0.42 & -0.17 & 1.23 & 1.9 \\
BE & 1.99 & 1.59 & 1.55 & 1.76 & 0.91 & 0.56 & -0.36 & 0.69 & 0.41 \\
BG & -1.77 & -1.76 & -3.11 & -3.54 & -3.35 & -1.37 & 0.63 & -0.09 & -0.21 \\
CY & 0.29 & -0.73 & 0.45 & -0.55 & -0.69 & -3.22 & -2.93 & -0.50 & -1.84 \\
CZ & 0.07 & 0.85 & 0.65 & 0.59 & 0.12 & 0.21 & 0.52 & 0.25 & 0.36 \\
DE & 2.35 & 2.47 & 2.73 & 2.88 & 2.21 & 1.12 & 0.85 & 192 & 1.88 \\
DK & 1.18 & 0.98 & 0.80 & 1.15 & 1.28 & 1.4 & -0.23 & 1.85 & 1.87 \\
EE & -3.16 & -1.32 & -2.46 & -2.88 & -1.04 & 2.59 & 3.25 & 0.36 & 0.30 \\
EL & -0.80 & -0.60 & -0.29 & -0.83 & -1.37 & -2.77 & -3.04 & -3.58 & -3.61 \\
ES & -1.25 & -0.96 & -1.45 & -0.79 & -1.45 & -0.31 & -0.44 & -2.35 & -2.42 \\
FI & 1.86 & 1.33 & 1.66 & 1.67 & 0.92 & 0.18 & -0.61 & 0.79 & 0.69 \\
FR & 1.2 & 1.5 & 0.98 & 1.39 & 0.75 & -0.20 & -1.01 & -0.10 & -0.41 \\
HR & -0.55 & -0.03 & -1.02 & -0.62 & -1.25 & -1.03 & -0.74 & -0.91 & -1.15 \\
HU & -2.19 & -0.84 & -0.01 & -1.64 & -1.69 & -0.69 & 0.57 & -0.80 & -0.88 \\
IE & -0.98 & -0.95 & -1.16 & 0.19 & -0.79 & 0.34 & -0.74 & -1.42 & -1.21 \\
IT & 0.61 & 0.97 & 0.83 & 1.72 & 0.67 & -0.83 & -1.26 & -0.50 & -0.65 \\
LT & -0.94 & -1.71 & -1.92 & -1.76 & -0.93 & 2.22 & 2.80 & -0.98 & 0.23 \\
LU NA & NA & NA & NA & & 3.67 & 2.45 & 1.30 & 3.79 & 3.47 \\
LV & -2.96 & -3.05 & -4.81 & -4.38 & -2.22 & 2.76 & 2.36 & -1.11 & -0.34 \\
MT NA NA & 0.31 & 0.15 & 0.95 & 0.58 & -1.85 & -1.00 & 0.76 & 1.34 \\
NL & 2.33 & 1.88 & 1.80 & 1.81 & 2.17 & 0.13 & 0.44 & 2.55 & 2.39 \\
PL & NA & -0.57 & 0.21 & 0.05 & -0.76 & -0.85 & -0.25 & -0.71 & -0.49 \\
PT & -0.16 & -0.32 & -0.30 & -0.05 & -1.43 & -2.18 & -2.04 & -2.18 & -2.21 \\
RO & -1.88 & -4.71 & -1.99 & -2.72 & -1.00 & -0.62 & 0.86 & -0.15 & -0.24 \\
SE & 1.87 & 1.77 & 1.88 & 1.55 & 1.55 & 0.64 & 1.46 & 1.57 & 1.39 \\
SI & 0.31 & 0.82 & 0.77 & -0.15 & 0.26 & -0.42 & 0.21 & 0.45 & 0.39 \\
SK & -1.87 & -0.84 & 0.21 & -0.70 & -0.92 & 0.08 & 0.46 & -0.95 & -0.03 \\
UK & -0.38 & 0.71 & 0.17 & 0.75 & 1.95 & 1.61 & -0.87 & 0.12 & -0.12 \\
\hline
\end{tabular}

\begin{tabular}{|c|c|c|c|c|c|c|c|c|c|}
\hline & 2004 & 2005 & 2006 & 2007 & 2008 & 2009 & 2010 & 2011 & 2012 \\
\hline$\overline{\mathrm{AT}}$ & 1.33 & 0.99 & 1.13 & 1.51 & 1.23 & 0.66 & 0.84 & 0.68 & 0.50 \\
\hline BE & 1.24 & 1.20 & 0.89 & 1.7 & 0.73 & 0.89 & 0.82 & -0.71 & 0.19 \\
\hline BG & -1.37 & -1.35 & -2.20 & -2.78 & -2.29 & -1.75 & -0.60 & -0.29 & -1.10 \\
\hline CY & -0.10 & -0.96 & 0.36 & -0.42 & -0.71 & -1.86 & -1.46 & -1.50 & -1.40 \\
\hline $\mathrm{CZ}$ & 0.39 & 0.86 & 0.67 & 0.70 & 0.45 & 0.42 & -0.31 & -0.28 & -0.30 \\
\hline DE & 1.88 & 1.82 & 1.84 & 2.2 & 1.76 & 1.21 & 1.59 & 1.54 & 1.29 \\
\hline DK & 0.72 & 0.94 & 0.98 & 1.10 & 1.6 & 0.89 & 0.79 & 1.63 & 1.3 \\
\hline EE & -2.24 & -0.94 & -1.62 & -1.90 & -0.73 & 1.7 & 1.47 & 1.12 & -1.23 \\
\hline EL & -0.95 & -1.23 & -1.12 & -1.50 & -1.39 & -2.43 & -2.35 & -1.46 & -0.10 \\
\hline ES & -1.23 & -1.13 & -1.32 & -0.95 & -1.04 & -0.93 & -0.88 & -0.71 & 0.00 \\
\hline FI & 1.49 & 1.2 & 1.30 & 1.28 & 0.56 & 0.00 & 0.17 & -0.5 & -0.44 \\
\hline FR & 0.68 & 0.65 & 0.52 & 0.74 & 0.57 & 0.18 & -0.19 & -0.43 & -0.37 \\
\hline HR & -0.48 & -0.38 & -1.13 & -0.91 & -0.38 & -1.14 & -0.71 & 0.22 & -0.09 \\
\hline HU & -1.73 & -0.96 & -0.45 & -1.33 & -1.52 & -0.61 & -0.12 & -0.61 & 0.37 \\
\hline IE & -0.77 & -0.72 & -0.56 & 0.31 & -0.70 & 0.22 & 0.12 & -0.41 & 0.32 \\
\hline IT & 0.15 & 0.31 & 0.24 & 0.84 & 0.34 & -0.46 & -0.42 & -0.48 & -0.54 \\
\hline LT & -0.59 & -0.82 & -1.11 & -1.05 & -0.34 & 0.91 & 1.1 & -0.50 & 0.23 \\
\hline LU NA & NA & & & & 3.25 & 2.17 & 2.30 & 1.92 & 1.72 \\
\hline LV & -2.05 & -1.99 & -3.38 & -2.89 & -1.72 & 1.54 & 1.32 & 0.02 & -0.65 \\
\hline MT NA & & 0.10 & 0.15 & 0.67 & 0.37 & -0.89 & -0.83 & 0.21 & 0.54 \\
\hline NL & 1.81 & 1.55 & 1.67 & 1.67 & 1.78 & 0.75 & 1.28 & 1.53 & 1.62 \\
\hline PL NA & & -0.44 & -0.24 & -0.17 & -0.43 & -0.01 & -1.56 & -0.64 & -1.09 \\
\hline PT & -0.47 & -0.90 & -0.73 & -0.73 & -1.23 & -1.94 & -2.04 & -1.03 & -0.13 \\
\hline RO & -1.22 & -2.40 & -1.09 & -1.60 & -1.00 & -0.11 & -0.27 & 0.43 & -0.68 \\
\hline SE & 1.47 & 1.31 & 1.53 & 1.32 & 1.18 & 0.92 & 0.79 & 0.59 & 0.63 \\
\hline SI & 0.48 & 0.82 & 0.84 & 0.28 & 0.30 & -0.34 & 0.34 & 0.84 & 0.73 \\
\hline SK & -1.22 & -0.85 & -0.14 & -0.39 & -0.36 & -0.64 & -0.43 & -0.58 & -0.17 \\
\hline UK & -0.35 & 0.52 & 0.23 & 0.48 & 0.24 & 1.29 & -0.67 & -0.17 & -0.88 \\
\hline
\end{tabular}


off, but decrease of MI index values manifested later - in Netherland in the following year and in the UK in 2010. In comparison with the precrisis year 2004 to 2012, after the turbulence in the early years of the crisis Estonia, Hungary, Latvia, Lithuania, Poland, Slovenia, Slovakia, Netherlands and Luxembourg have increased aggregated $\mathrm{MI}$ index values - except Netherlands and Luxembourg this happened in accession countries to the EU after 2004. Other countries did not reach in 2012 the values of MI index from pre-crisis period; Luxembourg lacks data for pre-crisis period but the overall MI index in this country is the highest since 2008.
For the whole time period Luxembourg, Germany, Netherland and Sweden ranked up most often to 5th place and these countries can be considered for the most stable in terms of $\mathrm{MI}$ due to highest values of the aggregated MI index and mean $\mathrm{MI}$ index in pre-crisis period and immediately thereafter. Austria, Denmark and Belgium can be considered for relatively stable economies which ranked highest positions with significant variations only in 2010. According to our results Portugal, Greece, Spain, Romania (until 2009 also Slovakia, Latvia, Lithuania) could be considered for countries with most disturbed macroeconomic imbalances. After first

\section{Fig. 2: External MI index In1-5 vs. Mean External MI index}

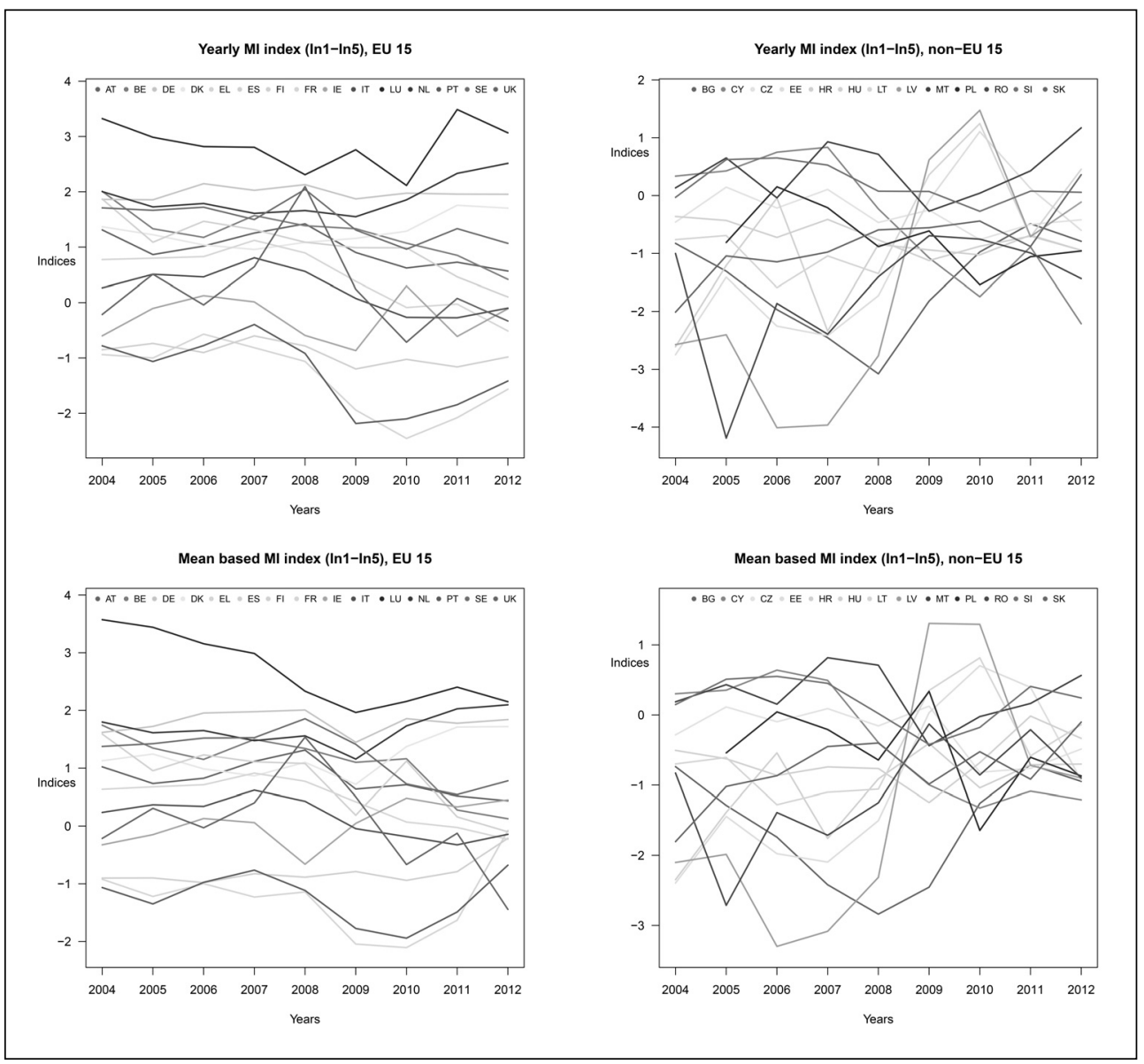

Source: own 


\section{Fig. 3: Internal MI index In6-10 vs. Mean Internal MI index}

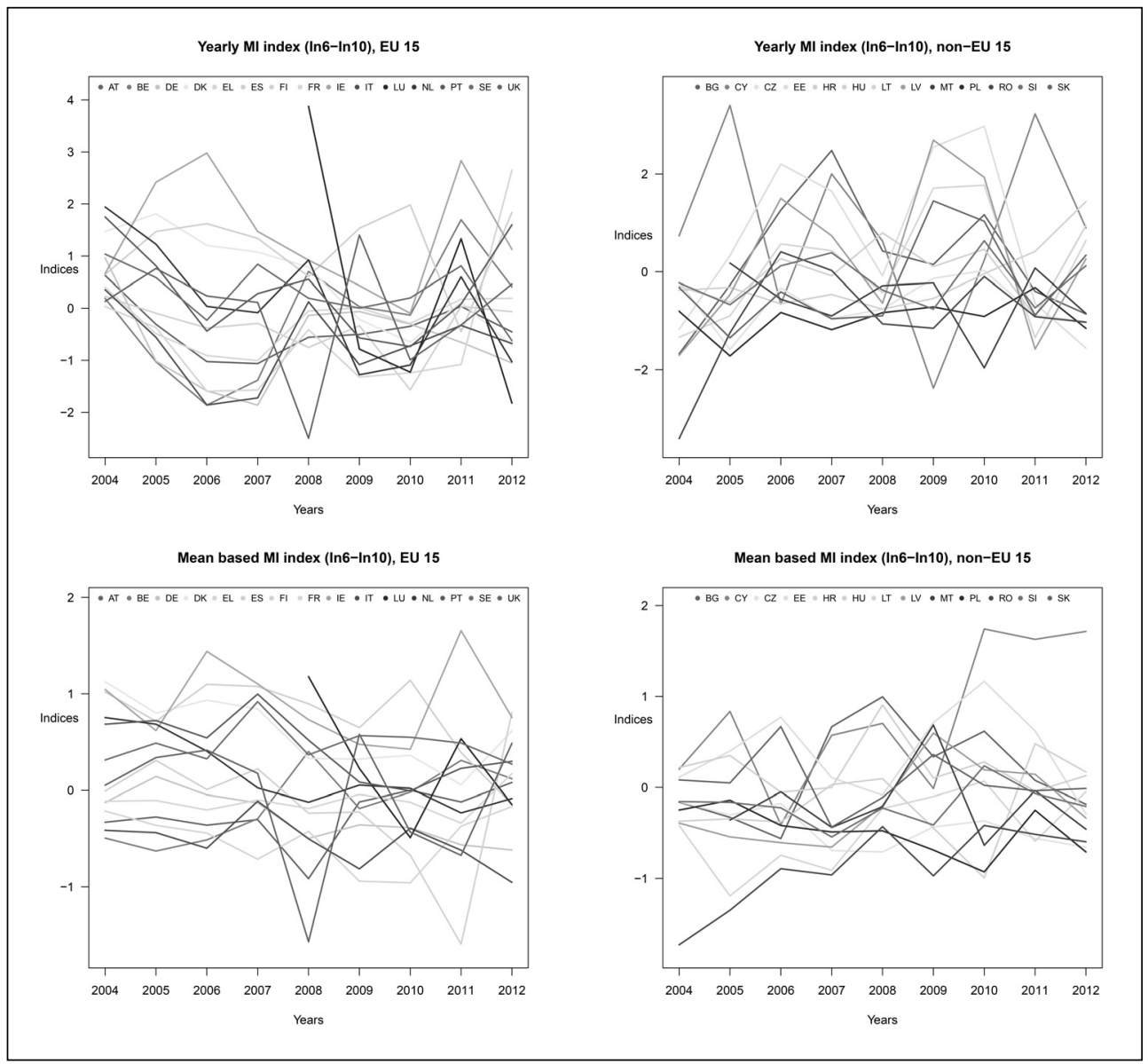

Source: own

impact of the crisis Greece, Italy and Portugal worsen in average its ranking position the most while Estonia, Latvia and Lithuania reached the best average ranking improvement mainly due to short-term improvement (for example Latvia in 2009 and 2010). From Ml point of view, the results showed that Post-Communist countries dealt with economic crisis better than some countries from south of the EU.

Development of MI was divided on external MI (In1-5) and internal MI (In6-10). Ideal situation would be country with positive aggregated MI index accompanied by positive partial external and internal MI indices. This case did not occur in any country except Sweden with fluctuations of the internal MI index in 2006 and 2012. The EU15 and Non-EU15 countries had parallel evolution of overall and external Ml indices, i.e. EU15 countries have in general (except Spain, Portugal, Ireland and Greece) positive index values compared with non-EU15 countries with prevalence of negative indices values (Fig. 2). According to AMR data, long-term positive values of Net international investment position and stable Current account balance could belong to factors which could explain these results.

In terms of internal MI for the most stable countries can be considered Ireland, Sweden 


\section{Fig. 4: Partial external and internal MI indices}

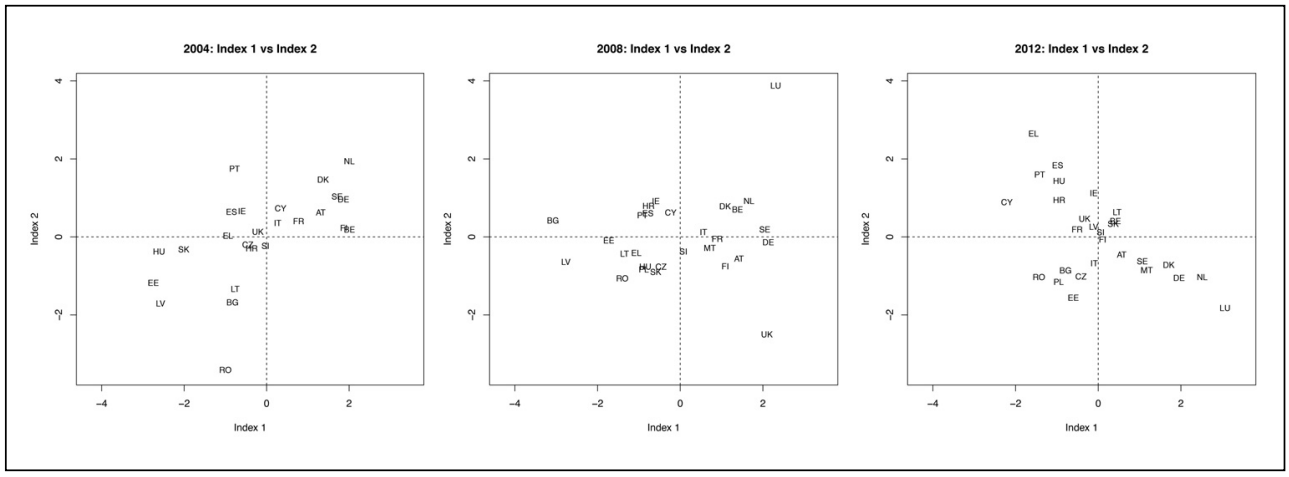

Source: own

and Spain where almost only positive values were measured; in other countries this indicator had large fluctuations. Belgium, Slovakia, Latvia and Lithuania reached the highest improvement and positive partial internal MI index after 2008 - high weight of positive rate of Private sector credit flow on GDP could be one of the factors in explaining improvement and positive internal $\mathrm{Ml}$ index in these countries. On the contrary Denmark and Luxembourg had evident decrease. For countries without significant fluctuations of internal Ml could be considered French and Austria (especially after 2008) but these countries did not reach positive values (Fig. 3). Larger discrepancies among EU countries were assigned using mean internal MI index what was indicated by correlations, therefore we do not recommend to use mean internal MI index.

Graphical representation of the EU position in relation to the external and internal MI indices constructed using the first method based on one year data illustrate Fig. 4 which provides the evolution of partial indices over time.
Configuration of countries in quadrants was very variable although typical tendencies for precrisis, crisis and partly aftermath periods can be seen. The most typical trend is in upper right and lower quadrant where dominated countries of Western Europe, Benelux and Scandinavia in 2004 these countries reached positive values in both partial MI indexes while in 2012 they maintained the positive values only in the lower right quadrant (external MI index). The Baltic countries, the Visegrad countries and Southern Europe have been dominated in the upper and lower left quadrants. Positive values of both partial MI indices reached the countries in the upper right quadrant; opposite, i.e. external and internal $\mathrm{Ml}$ reached countries in lower left quadrant. While in 2004 was among indices direct relationship in 2012 it was vice versa. Countries of Western Europe, Scandinavia and the Benelux maintained high positive values of external $\mathrm{Ml}$ index during crisis but these countries had significant deterioration of internal MI index. Southern European countries maintain their position in the upper left quadrant

\section{Tab. 10: Mean based MI index - estimated values for 2013}

\begin{tabular}{l|c|c|c|c|c|c|c|c|c|c|c|c|c|c|c} 
EU 15 & AT & BE & DE & DK & ES & FI & FR & IT & LU & NL & PT & SE & UK & IE & EL \\
\hline In1-10 & 0.09 & -0.45 & 1.34 & 1.75 & -0.14 & -0.16 & -0.73 & -0.39 & 2.63 & 1.58 & -0.71 & 0.35 & -0.51 & 0.14 & 0.13 \\
\hline $\begin{array}{l}\text { Non } \\
\text { EU15 }\end{array}$ & BG & CY & CZ & EE & HU & LT & LV & PL & RO & SI & SK & HR & MT & & \\
\hline In1-10 & -1.014 & -0.873 & -0.291 & -1.366 & -0.223 & -0.079 & -0.547 & NA & -1.035 & 1.245 & -0.139 & -0.407 & 0.631 & & \\
\hline
\end{tabular}


i.e. they had a positive values of internal MI index. Some Visegrad and Baltic countries improve mainly its internal $\mathrm{MI}$ in first crisis years (in 2012 Slovakia, Lithuania and Slovenia also improved external MI index).

When we used mean weights of $\mathrm{MI}$ indices for assessment of overall Ml for 2013 and construct ranking of EU countries according accessed values for 2013 we have briefly found that Austria, Germany, Denmark, Ireland, Sweden, Netherland, Malta, Luxembourg, Slovenia did not seems to represent $\mathrm{Ml}$ in the sense of the MIP. These countries had estimated mean aggregated $\mathrm{Ml}$ index values positive (Tab. 10). Position of Greece could be counted for controversial. These results have not fully matched with AMR (2015), where also in Czech Republic, Latvia, Lithuania (estimated value of mean based MI index close zero), Slovakia and Poland did not seem to represent $\mathrm{MI}$ in the sense of the MIP. However, changes in $\mathrm{Ml}$ indicators values are reflected in $\mathrm{Ml}$ indices construct and their values. Therefore, our findings enable us to suggest our MI indices for practical use within AMR reports as general alternative assessment tool of macroeconomic imbalances within EU countries.

\section{Conclusions}

In this article we proposed innovative alternative measurement tool of macroeconomic imbalances which matched with our assumption that the prediction ability of older values of the index is quite good in pre-crisis period, it deteriorates during a crisis and then it improves once the crisis is retreating. The main motivation for the construction of the Ml indices was to streamline presentation and monitoring of $\mathrm{Ml}$ progress in solving of the impact of the economic and financial crisis in the EU member states and to make these indicators more comprehensible for a wider audience as well as to map the position of the EU countries in terms of MI what constructed indices fulfil. Proposed methodology of construction of aggregated and partial MI indices using PCA may be usable for the Eurostat reports including AMR. Proposed indices could be used as relative indicators of the effectiveness of policies actions aimed on mitigation of macroeconomic imbalances in different EU countries; however this issue needs future investigation.

Comparison of countries based on $\mathrm{Ml}$ indices enables us to identify countries which seem to be relatively more macroeconomic stable as other EU countries. Luxembourg, Germany, Netherland and Sweden can be considered for the most stable European countries from MI point of view. Used methodology and results of this study indicate that positive and stable values of Current account balance and Net international investment position as \% of GDP have high weight on macroeconomic stability of EU countries. Financial stability reflected in internal MI index will need future in-depth investigation and monitoring in all EU countries.

As political and scientific debate about monitoring of $\mathrm{Ml}$ in the EU will continue, modifications in component structure of proposed Ml indices will be required. Shifts in the ranking positions due to influences of economic, financial and refuge crisis could inspire scientific discussion about macroeconomic stability of the EU countries. Another step how to develop this topic could be seen in further investigation of relation between overall macroeconomic imbalances and auxiliary MI indicators.

\section{References}

AMR. (2014). Alert Mechanism Report. Brussels: European Commission.

AMR. (2015). Alert Mechanism Report. Brussels: European Commission.

AMR. (2016). Alert Mechanism Report. Brussels: European Commission.

Angelini, E. C., \& Farina, F. (2012). Current account imbalances and systemic risk within a monetary union. Journal of Economic Behavior \& Organization, 83, 647-656. https://doi.org/10.1016/j.jebo.2012.05.009.

Angelini, E., Dieppe, A., \& Pierluigi, B. (2015). Modelling internal devaluation experiences in Europe: Rational or learning agents? Journal of Macroeconomics, 43, 81-92. https://doi.org/10.1016/j.jmacro.2014.08.008.

Auzina-Emsina, A. (2014). Labour productivity, economic growth and global competitiveness in post-crisis period. Procedia Social and Behavioral Sciences, 156, 317-321. https://doi.org/10.1016/j.sbspro.2014.11.195.

Babecký, J., Havránek, T., Matějů, J., Rusnák, M., Šmídková, K., \& Vašíček, B. (2012). Leading indicators of crisis incidence evidence from developed countries [ECB Working paper No. 1486]. Frankfurt am Main: European Central Bank.

Begler, H., \& Nitsch, V. (2014). Wearing corset, losing shape: The euro's effect on 
trade imbalances. Journal of Policy Modeling, 36(1), 136-155. https://doi.org/10.1016/j. jpolmod.2013.03.015.

Bolcárová, P., \& Kološta, S. (2015). Assessment of sustainable development in the EU 27 using aggregated SD index. Ecological Indicators, 48, 699-705. https://doi. org/10.1016/j.ecolind.2014.09.001.

Breiman, L. (2001). Random Forests. Machine Learning, 45(1), 5-32. https://doi. org/10.1023/A:1010933404324.

Campos-Soria, J. A., Inchausti-Sintes, F., \& Eugenio-Martin, J. L. (2015). Understanding tourists' economizing strategies during the global economic crisis. Tourism Management, 48, 164-173. https://doi.org/10.1016/j.tourman.2014.10.019.

Catte, P., Cova, P., Pagano, P., \& Visco, I. (2011). The role of macroeconomic policies in the global crisis. Journal of Policy Modeling, 33, 787-803. https://doi.org/10.1016/j. jpolmod.2011.06.001.

Collignon, S. (2012). Macroeconomic imbalances and comparative advantages in the Euro Area. Brussels: ETUI.

Collignon, S. (2013). Macroeconomic imbalances and competitiveness in the Euro Area. Transfer: European Review of Labour and Research, 19(1), 1-25. https://doi. org/10.1177/1024258912469467.

Csortos, O., \& Szalai, Z. (2013). Assessment of macroeconomic imbalance indicators. MNB BULLETIN, October.

Domonkos, T., Ostrihoň, F., Šikulová, I., \& Širaňová, M. (2017). Analysing the Relevance of the MIP Scoreboard's Indicators. National Institute Economic Review, 239(1), 32-52. https://doi.org/10.1177/002795011723900112.

Dreher, A. (2006). Does globalization affect growth? Evidence from a new index of globalization. AppliedEconomics, 38,1091-1110. https://doi.org/10.1080/00036840500392078.

Eugenio-Martin, J. L., \& Campos-Soria, J. A. (2014). Economic crisis and tourism expenditure cutback decision. Annals of Tourism Research, 44, 53-73. https://doi. org/10.1016/j.annals.2013.08.013.

Florida, R., Mellander, Ch., \& Stolarick, K. (2011). Creativity and Prosperity: The Global Creativity Index. Toronto: Martin Prosperity Institute.

Fogli, A., \& Perri, F. (2015). Macroeconomic volatility and external imbalances. Journal of Monetary Economics, 69, 1-15. https://doi. org/10.1016/j.jmoneco.2014.12.003.
Gossé, J.-B., \& Serranito, F. (2014). Long-run determinants of current accounts in OECD countries: Lessons for intra-European imbalances. Economic Modeling, 38, 451-462. https://doi.org/10.1016/j.econmod.2014.01.008.

Gugler, K., Weichselbaumer, M., \& Zulehner, Ch. (2015). Competition in the economic crisis: Analysis of procurement auctions. European Economic Review, 73, 35-57. https://doi. org/10.1016/j.euroecorev.2014.10.007.

Jollife, I. T. (2002). Principal Component Analysis (2nd ed.). New York: Springer.

Klepáč, V., \& Hampel, D. (2018). Predicting bankruptcy of manufacturing companies in EU. E\&M Ekonomie a Management, 21(1), 159-174. https://dx.doi.org/10.15240/tul/001/2018-1-011.

Knedlik, T., \& Schwainitz, G. (2011). Macroeconomic Imbalances as Indicators for Debt Crises in Europe (IWH discussion paper No. 12). Halle Institute for Economic Research.

Kološta, S., Sabelová, L., \& Král', P. (2018). Assessment of National Program of Learning Regions in Slovakia - Design and Testing. DANUBE: Law, Economics and Social Issues Review, 9(2), 117-133. https://doi.org/10.2478/ danb-2018-0008.

$\mathrm{Li}, \mathrm{Ch}$. (2018). Evaluation of the financial and economic development of the European Union member states on basis of multiple indicators changed to multiple objectives. E\&M Ekonomie a Management, 21(4), 19-32. https://dx.doi.org/10.15240/tul/001/2018-4-002.

Markovitz, Y., Boer, D., \& van Dick, R. (2014). Economic crisis and the employee: The effects of economic crisis on employee job satisfaction commitment and self-regulation. European Management Journal, 32, 413-422. https://doi.org/10.1016/j.emj.2013.09.005.

Mauro, F., \& Pappada, F. (2014). Euro area external imbalances and the burden of adjustment. Journal of International Money and Finance, 48, 336-356. https://doi.org/10.1016/j. jimonfin.2014.05.017.

Mazurek, J., \& Mielcová, E. (2017). Is consumer confidence index a suitable predictor of future economic growth? An evidence form the USA. E\&M Ekonomie a Management, 20(2), 30-45, https://doi.org/10.15240/tul/001/2017-2-003.

Querimi, Q., \& Sergi, B. S. (2017). The nature and the scope of the global economic crisis' impact on employment trends and policies in South East Europe. Journal of International Studies, 10(4), 143-153. https://doi.org/10.14254/2071-8330.2017/10-4/11. 
R Core Team. (2016). R: A language and environment for statistical computing. Vienna: $R$ Foundation for Statistical Computing. Retrieved from https://www.R-project.org/.

Sasiana, M., \& Satelli, A. (2012). Corruption Perceptions Index 2012 Statistical Assessment. Luxembourg: Publications Office of the European Union.

Sigg,C.D.,\&Buhmann,J.M.(2008).ExpectationMaximization for Sparse and Non-Negative PCA. In Proceedings of the 25th International Conference on Machine Learning (pp. 960-967). https://doi.org/10.1145/1390156.1390277.

Statistical annex AMR. (2015). Statistical annex of Alert Mechanism Report 2015. European Commision. Available from http://ec.europa.eu/eurostat/web/macroeconomicimbalances-procedure/publications.

Stracca, L. (2014). Financial imbalances and household welfare: Empirical evidence from the EU. Journal of Financial Stability, 11, 82-91. https://doi.org/10.1016/j.jfs.2013.12.001.

Tatulescu, A., \& Patruti, A. (2014). Structural Funds And Economic Crises: Romania's Absorption Paradox. Procedia Economics and Finance, 16, 64-72. https://doi.org/10.1016/ S2212-5671(14)00775-8.

Zhao, X., Jiang, X., \& Li, Z. (2014). The impact of the economic crisis on the financial performance of multinational corporations. International Review of Economics and Finance, 37, 55-68. https://doi.org/10.1016/j. iref.2014.11.013.
Zozri, M., Chudik, A., \& Dieppe, A. (2012). Thousands of models, one story: Current account imbalances in the global economy. Journal of International Money and Finance, 31 , 1319-1338. https://doi.org/10.1016/j. jimonfin.2012.02.003.

Ing. Stanislav Kološta, PhD. Matej Bel University Faculty of Economics Department of Public Economics and Regional Development Slovakia stanislav.kolosta@umb.sk

RNDr. Pavol Král', PhD. Matej Bel University Faculty of Economics Department of Quantitative Methods and Information Systems Slovakia pavol.kral@umb.sk

Ing. Filip Flaška, PhD. Matej Bel University Faculty of Economics Department of Public Economics and Regional Development Slovakia filip.flaska@umb.sk 


\section{Appendix}

\section{Tab. 11: Descriptive statistics of used annual headline indicators of MI in EU}

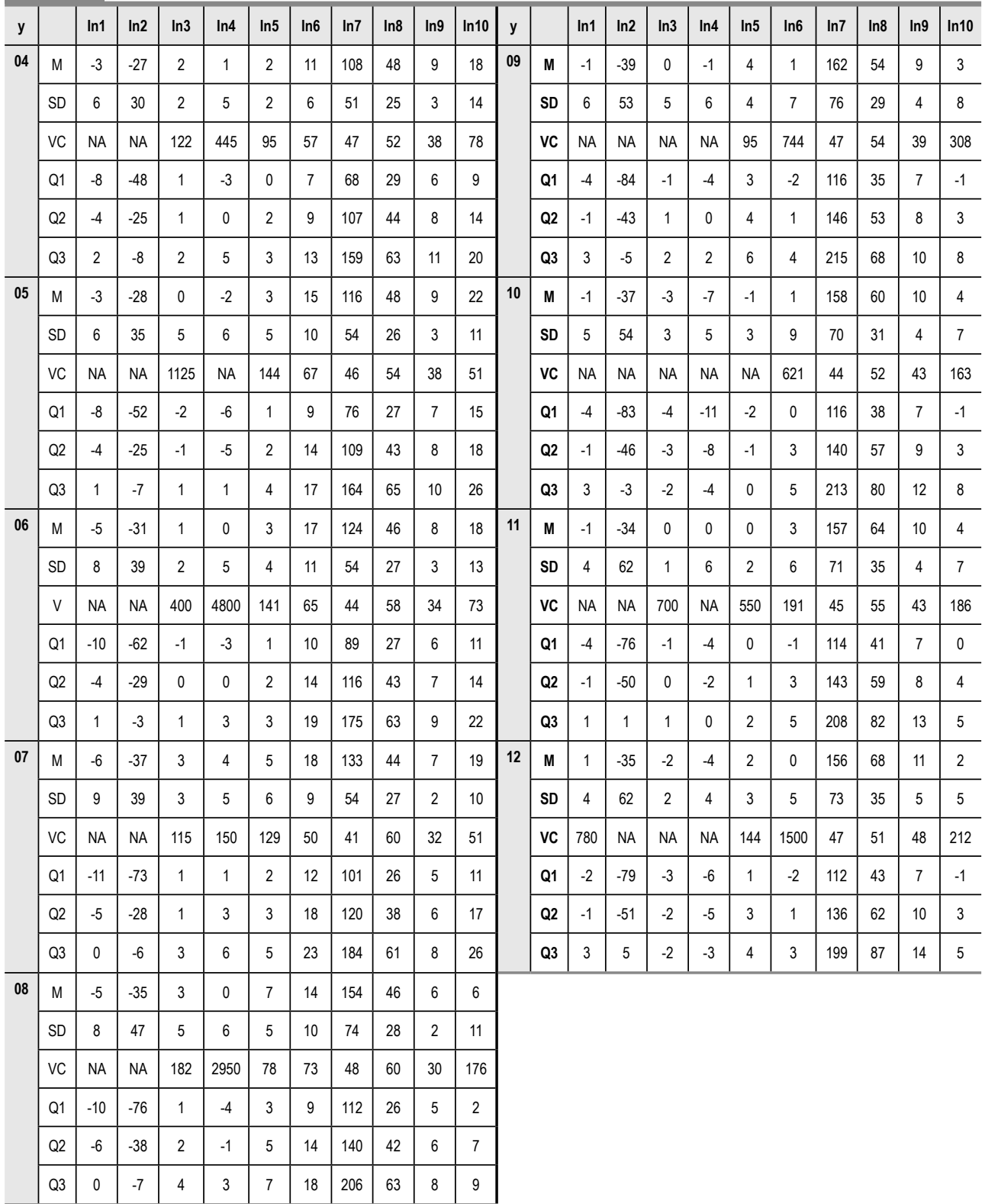




\title{
Abstract
}

\section{ALTERNATIVE MEASURES OF MACROECONOMIC IMBALANCES IN THE EU - DESIGN AND VERIFICATION}

\author{
Stanislav Kološta, Pavol Král', Filip Flaška
}

As a consequence of financial and economic crisis in the EU the macroeconomic imbalances (MI) have been monitored since 2012. Annual Alarm Mechanism Report (AMR) focused on assessment of MI contains the interlinkages between the real economy and the financial sector. From AMR data, we can get picture about the evolution of different $\mathrm{MI}$ indicators in the $\mathrm{EU}$, but complete picture about the overall situation of individual countries in the field of $\mathrm{MI}$ is missing. Therefore, we focused on design and verification of suitable alternative evaluation tool which AMR lacks, and which could be usable for decision making processes within European Commission. The main aim of the article is to propose aggregated and partial indices of MI using constrained PCA which can: i) provide a complex evaluation of each EU country on its global position in headline indicators; ii) make MI indicators more comprehensible for wider use; iii) design simple alternative assessment tool useful for monitoring whether measures taken by the EU and the member states are directed towards improving the macroeconomic balance. The proposed $\mathrm{Ml}$ indices are verified from a quantitative as well as qualitative point of view. Results of proposed assessment tools showed that: Luxembourg, Germany, Netherland and Sweden can be considered for the most stable EU countries from MI point of view; Post-Communist countries dealt with economic crisis better than some countries from south of the EU; after first crisis years the best improvement in MI index reached Baltic and Visegrad countries together with Luxembourg and Netherland; other EU countries in 2012 did not reach $\mathrm{Ml}$ index values from pre-crisis period. This study indicates that positive and stable values of current account balance and net international investment position as \% of GDP have high weight on macroeconomic stability of EU countries.

Key Words: Principal component analysis, macroeconomic imbalances, aggregated index, indicators.

JEL Classification: C8, E6.

DOI: 10.15240/tul/001/2019-1-003 